\title{
Retinoic acid receptor-independent mechanism of apoptosis of melanoma cells by the retinoid CD437 (AHPN)
}

\author{
$X$ Zhao $^{1}$, K Demary ${ }^{1}$, L Wong ${ }^{1}$, C Vaziri ${ }^{2}$, AB McKenzie ${ }^{3}$, \\ TJ Eberlein ${ }^{4}$ and RA Spanjaard ${ }^{\star, 1}$ \\ ${ }^{1}$ Department of Otolaryngology, Cancer Research Center, Boston University \\ School of Medicine, Boston, MA, USA \\ 2 Department of Medicine, Cancer Research Center, Boston University School of \\ Medicine, Boston, MA, USA \\ ${ }^{3}$ Department of Surgery, Brigham and Women's Hospital, Harvard Medical \\ School, Boston, MA, USA \\ ${ }^{4}$ Department of Surgery, Washington University School of Medicine, St. Louis, \\ MO, USA \\ * Corresponding author: Boston University School of Medicine, Cancer \\ Research Center, 715 Albany Street R903, Boston, MA 02118. \\ Tel: (617) 638-4811; Fax: (617) 638-5837; E-mail: rspan@bu.edu
}

Received 18.1.01; revised 20.3.01; accepted 9.4.01

Edited by D Green

\begin{abstract}
Retinoic acid (RA) induces differentiation of S91 melanoma cells through activation of RA receptor (RAR) $\gamma$ without affecting cell viability. The novel RAR $\gamma$-agonist CD437 (AHPN), however, also induces concomitant apoptosis through an unknown mechanism which was investigated here. By utilizing DNA microarray analysis, five apoptosis-associated, CD437-induced transcripts (CITs) were identified. Interestingly, all CITs are also regulated by p53 in a DNA damage response, and consistent with this interpretation, CD437 was found to cause DNA adduct-formation. However, p53 is not required for CD437-dependent regulation of CITs. Among this set of genes, induction of p21 WAF1/CIP1 is likely to be responsible for early S-phase growth-arrest of CD437-treated cells, whereas ei24 is a critical mediator of CD437-induced apoptosis in S91 cells. These data suggest an RARindependent mechanism in which CD437 causes DNA adduct-formation, resulting in induction of a p53-independent DNA damage response, and subsequent growth-arrest and apoptosis. CD437-mediated DNA adduct-formation may also explain its apoptotic effects in other cell types. Cell Death and Differentiation (2001) 8, 878-886.
\end{abstract}

Keywords: retinoic acid receptor; apoptosis; differentiation; CD437; melanoma

Abbreviations: RA, retinoic acid; RAR, RA receptor; RARE, RA response element; p53RE, p53 response element; Cdk, cyclin dependent kinase; Cdkl, Cdk inhibitor; CIT, CD437-induced transcript; Luc, Luciferase; 4NQ, 4-nitroquinoline N-oxide; DMSO, dimethyl sulfoxide; PI, propidium iodide; PARP, poly (ADP ribose) polymerase; SDS-PAGE, sodium dodecylsulfate-polyacrylamide gel electrophoresis

\section{Introduction}

Retinoic acid (RA) ${ }^{3}$ and other retinoids are small molecules derived from retinol (Vitamin A) which guide proper mammalian embryonic development by activating RARs, a class of ligand-dependent transcription factors which regulate gene expression through binding to RA response elements (RAREs). ${ }^{1,2}$ RA can also induce growth-arrest and differentiation of a large variety of tumor cells in vitro ${ }^{3}$ and mediate similar effects in some neoplastic tissues, ${ }^{4}$ which is the rationale behind the use of retinoids as pharmacological agents for differentiation and chemoprevention therapies in certain cancers. ${ }^{5,6}$

In order to understand the molecular basis of the effects of retinoids on the genetic program of tumor cells, we have utilized the S91 murine melanoma cell line as a model system for the etiology of this disease. RA slows replication of these cells by repressing expression of genes involved in cell division and proliferation, which is then subsequently followed by differentiation without affecting cell viability. ${ }^{7}$ Although RARs $\alpha, \beta$ and $\gamma$, and retinoid $\mathrm{X}$ receptors $\alpha$ and $\beta^{8-10}$ are expressed to varying degrees in S91 cells, differentiation appears to be solely mediated by RAR $\gamma{ }^{11}$ Interestingly, however, the RAR $\gamma$-specific agonist CD437 (6-(3-(1-adamantyl)-4-hydroxyphenyl)-2-naphthoic acid, or AHPN) not only induces differentiation, but also rapid concomitant apoptosis which can be detected after $8 \mathrm{~h}$ of treatment. The latter process is cycloheximide $(\mathrm{CHX})$ dependent and most likely requires new gene expression. ${ }^{11}$ The combined effects of CD437 may, therefore, represent a mixture of $\operatorname{RAR} \gamma$-dependent and independent gene expression-modulating activities. Consistent with this interpretation, it was reported that CD437 can induce apoptosis in RA-resistant cells ${ }^{12}$ and RAR-antagonists were incapable of blocking CD437-mediated apoptosis. ${ }^{13}$

At present, the mechanism behind the differential activities of RA and CD437, in particular as they relate to apoptosis, remain largely unknown. With the possible exception of the cyclin dependent kinase inhibitor (cdkl) p21 WAF1/CIP1, which appears to be universally induced by CD437, ${ }^{12,14-19}$ expression or activity of several other genes or gene products such as c-myc, ${ }^{20} \mathrm{AP}-1,{ }^{17,21}$ Nur77, ${ }^{17}$ GADD45, ${ }^{12,22}$ Cyclin A, ${ }^{16,19}$ Bcl-2, 12,14,15,17,18 $\mathrm{Bcl}-\mathrm{X}_{\mathrm{L}},{ }^{12,15,17,23} \mathrm{Bcl}-\mathrm{X}_{\mathrm{S}},{ }^{16} \mathrm{Bax}^{14,15,17,18} \mathrm{Bad},{ }^{16}$ p53, ${ }^{16,18,21,24}$ E2F-1, ${ }^{19}$ and caspases ${ }^{19,25,26}$ have been variously reported to be either unchanged, down or upregulated, with different kinetics and in a cell typedependent manner in response to CD437. Not surprisingly, it is difficult to discern a putative common CD437dependent mechanism among these findings. This is an important issue, because dissection of the CD437dependent signaling cascade could provide new insights into how this, and other novel conformationally-restricted 
retinoids regulate gene expression and change the fate of tumor cells, and this information may eventually aid in the development of new therapies.

In order to determine the mechanism of CD437-mediated apoptosis we again used the $S 91$ cell system because they are very sensitive to this compound. ${ }^{11}$ We have utilized gene expression DNA microarrays to apply a relatively unbiased and systematic genetic screen for transcripts which are specifically induced by CD437 but not by RA, and thus are specifically associated with apoptosis. In experiments desribed here, we identified five CD437induced transcripts (CITs), four of which had not been previously identified as such. Interestingly, they all belong to a category of p53-regulated cDNAs which are induced after DNA damage and consistent with this interpretation, we subsequently show that CD437, but not non-apoptotic retinoids, induces DNA adduct formation in a relatively cell type independent manner. However, our experiments using p53-depleted S91 cells suggest that there is an alternative, p53-independent regulatory pathway of CIT-regulation. Finally we established a critical physiological role for two CITs in CD437-induced growth-arrest and apoptosis.

Taken together, our results provide evidence for a novel model for the mechanism of the concomitant differentiation and apoptosis-inducing activities of CD437. One activity is that of an RAR $\gamma$-agonist which leads to growth-arrest and differentiation without causing cell death. The newlyidentified pathway is likely to be an RAR $\gamma$-independent DNA adduct-forming activity and, in S91 cells, this results in a p53-independent DNA damage-response. CD437mediated DNA damage may explain why most cells, irrespective of their sensitivity to $R A$, are responsive to CD437, and it may also explain the divergent genetic response to CD437.

\section{Results}

\section{Identification of CITs associated with apoptosis: evidence for an RAR-independent DNA damage response}

To identify CITs which mediate CD437-induced apoptosis in S91 cells, gene expression DNA microarrays were utilized in order to systematically screen for differentially expressed cDNAs between DMSO (control)-treated cells, and cells were treated for $8 \mathrm{~h}$ with CD437. This time frame was chosen because CD437-induced apoptosis becomes detectable after $8 \mathrm{~h}$ treatment. ${ }^{11}$ Five CITs were found to be induced by CD437, but not by RA or the RAR $\alpha$-agonist Am580 and the $\operatorname{RAR} \beta$-agonist CD2314, as shown in a Northern blot analysis

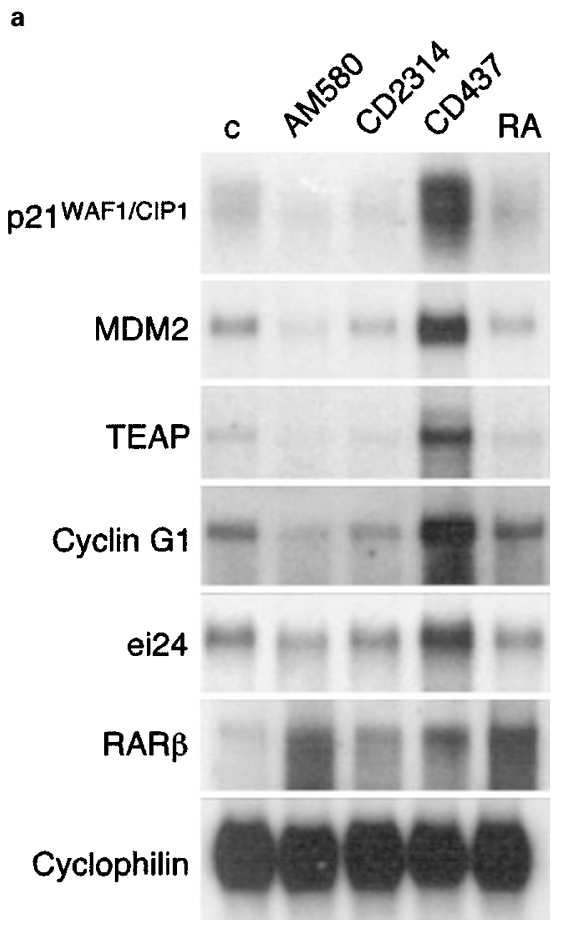

b
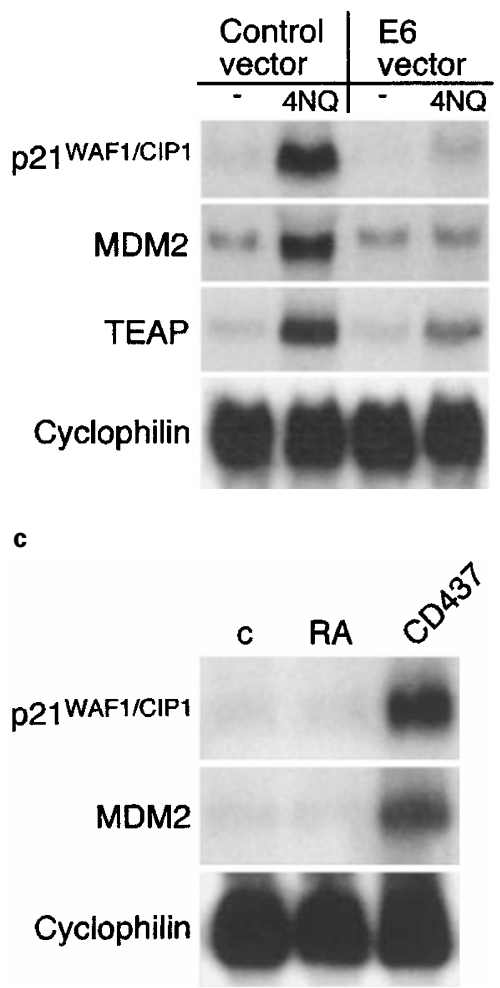

Figure 1 CD437 specifically induces expression of CITs. CITs are also induced by DNA damage caused by 4NQ in a p53-dependent manner. CD437 induces CITs in RA-resistant A375 cells as well. (a) Poly(A) ${ }^{+}$RNA was obtained from S91 cells treated for $8 \mathrm{~h}$ with DMSO (control), or with RAR $\alpha$-specific agonist Am580; RAR $\beta$-specific agonist CD2314; RAR $\gamma$-specific agonist CD437 or pan-RAR agonist RA. Three $\mu \mathrm{g}$ mRNA was loaded per lane, and Northern blots were hybridized with the indicated CDNA probes. Cyclophilin serves as loading control. (b) S91 cells were stably transfected with a control or E6-expressing retrovirus. Cells were then treated for $8 \mathrm{~h}$ with DMSO $(-)$ or $1 \mu \mathrm{g} / \mathrm{ml} 4 \mathrm{NQ}$, total RNA was obtained $(20 \mu \mathrm{g} / \mathrm{lane})$ and Northern blot analysis was performed with the indicated cDNA probes. Cyclophilin serves as loading control. (c) A375 cells were treated with DMSO, RA or CD437. Twenty $\mu \mathrm{g}$ total RNA was loaded per lane, blotted, and hybridized with the indicated cDNA probes. Cyclophilin serves as loading control 
in Figure 1A, and thus by this criteria CITs are all associated with apoptosis. As an internal control for the quality of the ligands, all compounds were shown to induce $R A R \beta$ expression. ${ }^{11}$ One of the CITs, p $21^{\mathrm{WAF} 1 / \mathrm{CIP} 1}$, was previously shown to be induced by CD437 and thus validates the assay. ${ }^{12,14-19}$ The other four CITs had not yet been identified as CD437-responsive transcripts and included: MDM2, an oncogene mainly known for its ability to inhibit p53-activity; ${ }^{27}$ TEAP (thymus-expressed acidic protein), an uncharacterized, novel cDNA which has been associated with thymocyte development, ${ }^{28}$ cyclin $\mathrm{G} 1$, a cyclin with unknown function which is induced after UV-B and ionizing radiation; ${ }^{29}$ and finally ei24, a cDNA which is induced in fibroblasts after treatment with etoposide or ionizing radiation; ${ }^{30}$ and which recently was shown to have apoptotic activity in these cells. ${ }^{31}$

A striking feature of four of five CITs ( $p 21^{\text {WAF } 1 / C I P 1}$, MDM2, cycG1 and ei24) is that they are known to be regulated by $p 53$ in response to DNA damage ${ }^{27,29,30}$ which may be indicative of a potentially RAR-independent mechanism of CD437-mediated gene regulation. To test this interpretation, we first wanted to establish whether S91 cells have a competent, p53-dependent DNA damage response and whether TEAP also falls into the same category as the other four genes. S91 cells were first stably infected with a retrovirus encoding the human papilloma virus E6 protein, which abrogates p53-function, or with control retrovirus. Control and E6-expressing cells were then treated for $16 \mathrm{~h}$ with DMSO (control) or the UVmimetic compound $4 \mathrm{NQ}$, total RNA was isolated and expression of TEAP was compared to that of the wellestablished DNA damage-regulated controls p21WAF1/CIP1 and MDM2 by Northern blot analysis. The results, shown in Figure 1B, demonstrate that $S 91$ cells have a functional, p53-dependent DNA damage response mechanism because $4 \mathrm{NQ}$ mediated induction of $p 21^{W A F 1 / C I P 1}$ and MDM2 which was significantly inhibited in the E6-transfectants. Interestingly, TEAP expression is similarly induced by $4 \mathrm{NQ}$ and blocked by depletion of p53, suggesting that TEAP is a novel p53-regulated, DNA damage-response gene.

A potential CD437-mediated DNA damage-response gene expression profile was also observed in the RAresistant, human melanoma cell line $A 375 .^{7}$ Cells were treated for $16 \mathrm{~h}$ with DMSO (control), RA or CD437 after which RNA was extracted and expression of $p 21_{\text {WAF1/CIP1 }}$ and MDM2 was again analyzed by Northern blot analysis. As shown in Figure 1C, both DNA damage-response genes were strongly induced by CD437. This suggests that related, if not fully conserved, mechanism(s) are operative in both murine and human melanoma cells, irrespective of the RAsensitivity of the cells, in agreement with a previous report. ${ }^{12}$

\section{CD437 induces DNA adduct-formation in a cell-type independent manner}

The previous results raise two important questions: Does CD437 induce DNA damage, and secondly, does it mediate regulation of CITs through $\mathrm{p53}$ ? To address the first issue, S91 were treated for $8 \mathrm{~h}$ with DMSO (control) and CD437, and also with the non-apoptotic retinoids RA and the chemically unrelated RAR $\gamma$-agonist CD666 ((E)-4-(1-Hydroxy-1-(5,6,7,8-
Tetrahydro-5,5,8,8-tetramethyl-2-naphthyl)-2-propenyl)benzoic acid). ${ }^{32}$ Chromosomal DNA was extracted and completely digested by nucleases. Nucleotides were labeled with ${ }^{32} \mathrm{P}$, resolved by $4-\mathrm{D}$ thin layer chromatography and detected by autoradiography. ${ }^{33}$ The results, shown in Figure 2 , reveal the existence of a new adducted nucleotide in samples from CD437-treated cells but it is absent in DNA from cells treated with the other non-apoptotic compounds. The adduct was also detected in 3T3 fibroblasts after CD437-treatment, but not in DMSO (control)-treated cells. These results suggest that CD437 induces DNA adduct-formation in a cell-type independent manner, and provide evidence that the observed DNA damage is linked to the onset of the apoptotic process (3T3 cells also undergo CD437-mediated apoptosis; data not shown).

\section{CD437 regulates expression of CITs in a p53-independent manner}

To answer the second question, S91 cells were transiently transfected with a promoter construct containing the p53
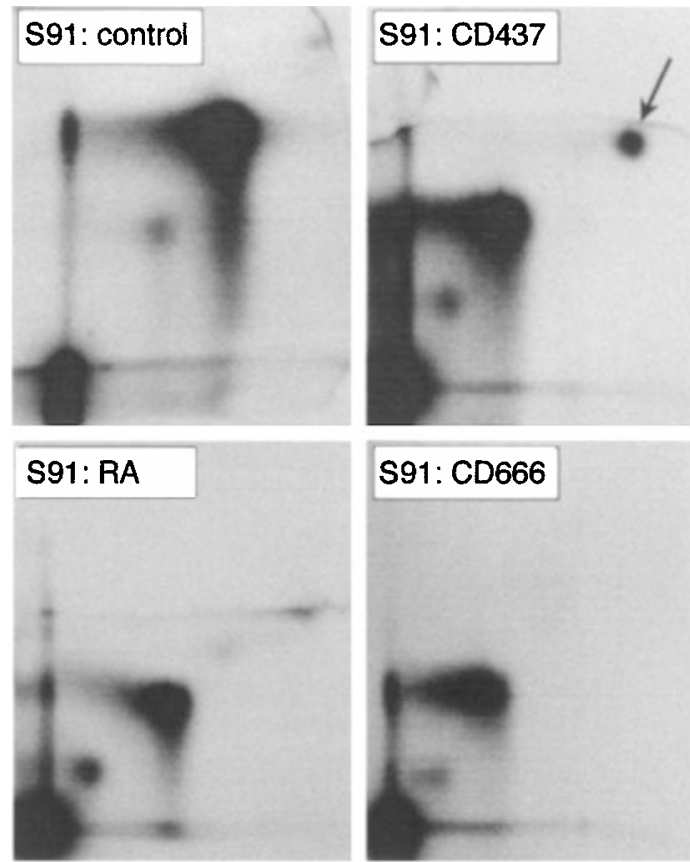

S91: CD666
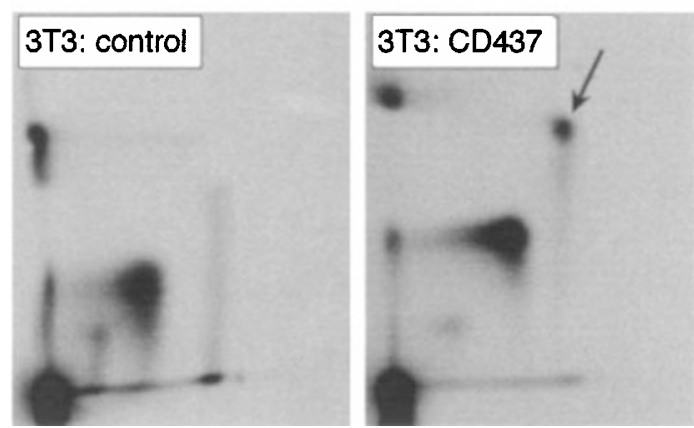

Figure 2 CD437 causes DNA adduct-formation in S91 cells as well as 3T3 fibroblasts. Arrow indicates CD437-specific DNA adduct after $8 \mathrm{~h}$ treatment which is absent in cells treated with non-apoptotic retinoids RA and RAR $\gamma$ agonist CD666 
response element ( $\mathrm{p} 53 \mathrm{RE}$ ) of MDM2 linked to a Luc reporter gene $^{34}$ and then treated for $16 \mathrm{~h}$ with DMSO (control), RA or CD437. As a positive control for CD437 agonist-activity, a similar reporter plasmid was transfected which contained the $\beta$ RARE. ${ }^{11}$ The results in Figure $3 A$ show that in contrast to the $\beta$ RARE, which was strongly activated by both CD437 and RA, a p53-dependent promoter was not activated by CD437 suggesting that CD437-treatment does not result in activation of p53. Two other reporter constructs with p53REs within larger segments of promoter regions of the $p 21^{W A F 1 / C I P 1}$ and MDM2 genes also failed to show induction (data not shown).

To further address this issue, we again utilized the stably transfected control and p53-deficient (E6-expressing) S91 cells. Cells were treated for $8 \mathrm{~h}$ with DMSO (control) or CD437, total RNA was isolated and expression of CITs was analyzed by Northern blot (Figure 3B). CD437 still induced expression of all CITs although basal levels of some of the CITs, such as p53-

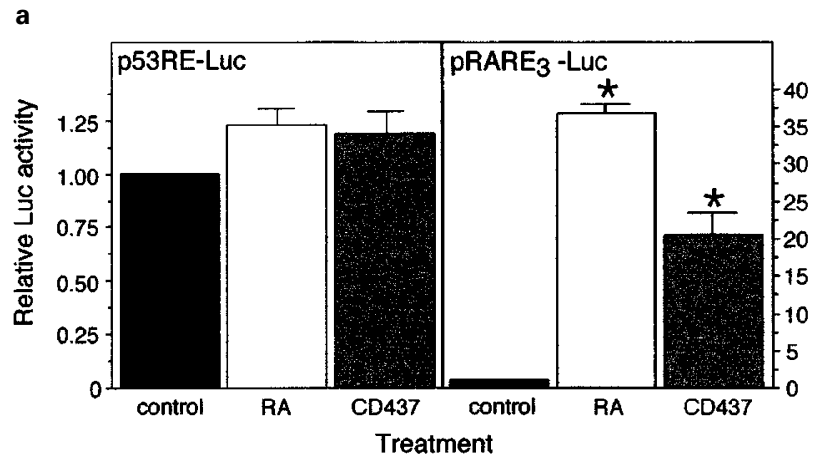

b

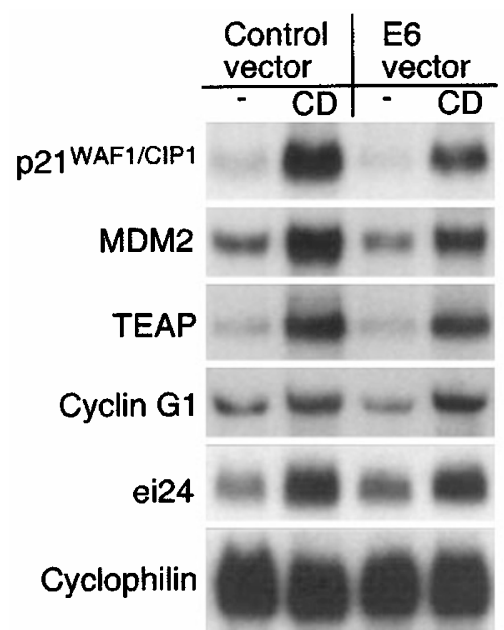

Figure 3 CD437-dependent induction of CITs in S91 cells is p53independent. (a) $\mathrm{S} 91$ cells were transfected with reporter plasmids containing the $\beta$ RARE and p53RE of RAR $\beta$ and MDM2, respectively, and treated with DMSO (control), RA or CD437 for $16 \mathrm{~h}$. Cells were harvested, and relative Luc activity was plotted after normalization for protein concentrations. Shown is a representative experiment done in duplicate and repeated at least four times. Error bars denote \pm S.E. ${ }^{*}, P<0.005$ versus control. (b) Stably transfected control S91 cells and E6-transfectants were treated for $8 \mathrm{~h}$ with DMSO $(-)$ or CD437 (CD), total RNA ( $20 \mu \mathrm{g} / \mathrm{lane})$ was loaded and expression of CITs was analyzed by Northern blot with the indicated cDNA probes. Cyclophilin serves as loading control regulated genes $p 21^{W A F 1 / C I P 1}$ and MDM2 are moderately reduced in the E6-transfectants.

Taken together, these results suggest that CD437 activates an alternative, p53-independent signaling pathway for CIT-regulation in S91 cells.

\section{CD437-mediated induction of $\mathrm{p} 21^{\mathrm{WAF} 1 / \mathrm{CIP} 1}$ is associated with early S-phase growth-arrest}

Next, we investigated the physiological consequences of CIT-induction for cell cycle progression and apoptosis. $\mathrm{p} 21^{\mathrm{WAF} 1 / \mathrm{CIP} 1}$ is a well-characterized cell cycle inhibitor, ${ }^{35,36}$ and induction of this gene can be expected to have a strong effect on the cell cycle. S91 cells were treated with RA or CD437 for various periods of time, and DNA content was determined by FACScan analysis (Figure 4A). RA-treatment shifted cells from $G_{2} / M$ to $G_{1} / G_{0}$, particularly between 8 and $16 \mathrm{~h}$, consistent with previous reports. ${ }^{7}$ Extended treatment with $R A$ resulted in a gradual increase of cells in $G_{1} / G_{0}$ but cell-viability was not affected. In contrast, within $4 \mathrm{~h}$ of CD437-treatment the $\mathrm{G}_{2} / \mathrm{M}$-phase had virtually disappeared and more cells had shifted to $G_{1} / G_{0}$. After $8 \mathrm{~h}$, cells appeared to be arrested at the $G_{1} / S$ check point. Cell viability was not yet significantly affected by $8 \mathrm{~h}$, but between 8 and $16 \mathrm{~h}$ the sub-G ${ }_{1}$ DNA content began to increase due to apoptosis, as previously shown by different, apoptosis-specific techniques. ${ }^{11}$ It is likely that induction of $\mathrm{p} 21^{\mathrm{WAF} 1 / \mathrm{CIP} 1}$ is responsible for the early S-phase arrest of CD437-treated cells.

To determine whether expression of other cell cycle genes may be regulated by CD437, additional Western blots were performed because many cell cycle regulators are controlled at the post-transcriptional level. ${ }^{37}$ Cells were again treated with DMSO (control), RA or CD437, harvested, whole cell extracts were made and protein expression was analyzed by immunoblotting. As shown in Figure 4B, p21 WAF1/CIP1 was strongly induced in S91 cells by CD437 after $2 \mathrm{~h}$ treatment consistent with our FACscan and mRNA expression studies. No evidence for RAdependent regulation of $\mathrm{p} 21^{\mathrm{WAF} 1 / \mathrm{CIP} 1}$ was observed in these cells, despite a putative RARE in its promoter. $^{38}$ Levels of cyclin D, but not those of cyclins $A$ and $E$ were down-regulated after $16 \mathrm{~h}$ treatment with CD437 which may reflect the beginning of differentiation. ${ }^{7,39}$ No change in expression levels of Cdkl p18 $18^{\mathrm{INK} 4 \mathrm{C}}$, Cdk's 2 and 4 , and E2F-1 were found (data not shown), indicating that CD437 changes expression of only a specific set of cell cycle proteins.

In addition to this set of effectors, expression levels of a group of proteins known to be involved in apoptotic processes were examined. CD437 did not induce changes in levels of p53, Bax, Bcl-2, Bcl- $\mathrm{X}_{\mathrm{L}}$ and caused only a very small reduction of caspase-3 substrate poly (ADP ribose) polymerase (PARP). Expression of Bad and $\mathrm{Bcl}-\mathrm{X}_{S}$ could not be detected (data not shown). These results provide further evidence ${ }^{11}$ that the mechanism of CD437-dependent apoptosis in S91 cells is not likely to be mediated by $p 53$, and argue against a critical role for alterations in the $\mathrm{Bcl}-2 / \mathrm{Bax}$ balance, or caspase-3 activation levels. 
a

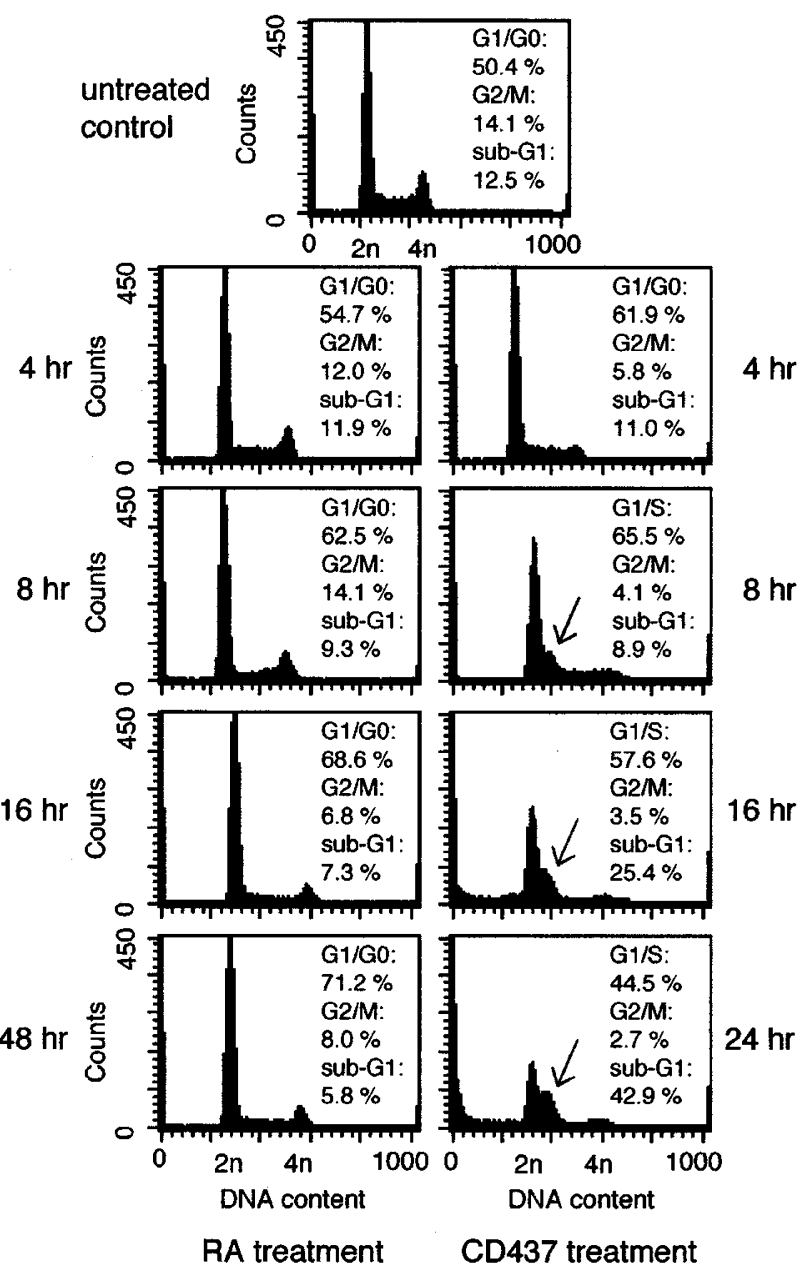

b
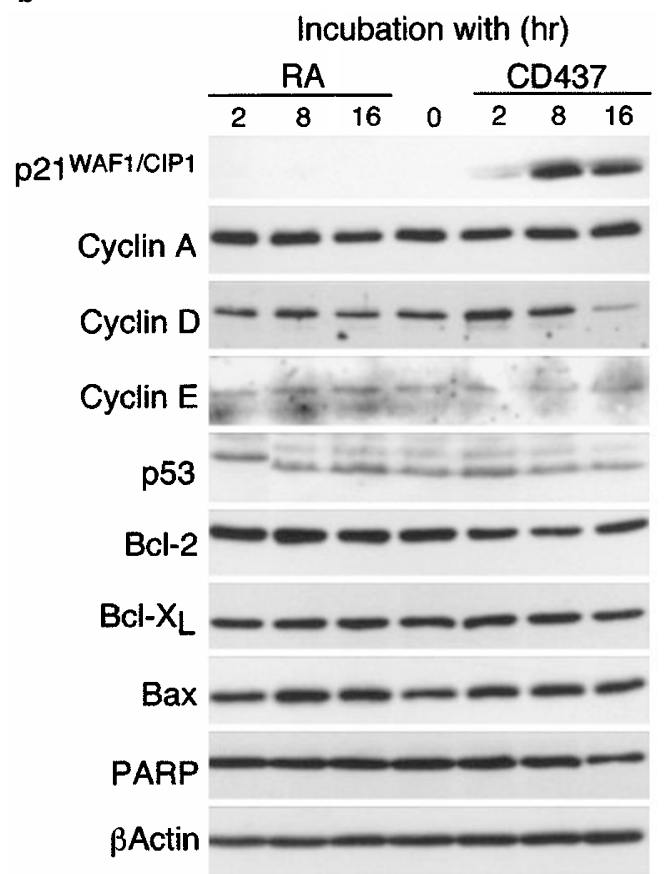

Figure 4 Cell cycle (a) and cell cycle gene expression (b) profile of CD437 and RA-treated S91 cells show CD437-specific, likely p21 WAF1/CIP1-mediated growth arrest in early S-phase. (a) FACScan analysis of control cells, or cells treated with RA or CD437 for the indicated time points. DNA content was analyzed by PI staining and FACScan analysis. \% sub-G ${ }_{1}$ DNA content due to apoptosis is indicated. Arrows indicate specific $\mathrm{G}_{1} / \mathrm{S}$ cell cycle check point. (b) Cells were treated for the indicated time points with RA or CD437. Whole cell extracts were made, and immunoblotted with the indicated antibodies. $\beta$ Actin serves as loading control

\section{ei24 Is a critical mediator of CD437-mediated apoptosis in S91 cells}

Recently, ei24 was shown to have pro-apoptotic activity when ectopically expressed in fibroblasts. ${ }^{31}$ Therefore, it seemed reasonable to establish a putative role for ei24 in CD437mediated apoptosis and we tested whether abrogation of ei24 expression could protect cells from the apoptotic activity of CD437. Cells were transfected with two different antisense oligonucleotides (AS1 and AS2, which are complementary to different regions spanning the translational start site of ei24 mRNA) and also with two matched sense control oligonucleotides (S1 and S2). After transfection, cells were treated for $20 \mathrm{~h}$ with CD437 and cell viability was determined by Trypan Blue staining. As shown in Figure 5, CD437 caused substantial cell death in both untransfected and mock transfected cells. However, transfection of AS1 and AS2 suppressed CD437-mediated cell death back to control levels, whereas control oligonucleotides S1 and S2 had no effect. In the absence of a commercially available antibody to native ei24, we were able to show that AS2 reduced expression of a FLAG-tagged transfected ei24 (Figure 5, inset). These results establish ei24 as a critical apoptotic mediator of CD437 in S91 cells.

\section{Discussion}

RA controls gene expression through activation of RARs. Previously, we showed that $\mathrm{RAR} \gamma$ in particular is likely to play a critical role in the process of differentiation of S91 melanoma cells. ${ }^{11}$ However, experiments with the RAR $\gamma$-agonist CD437 showed that this compound, apart from its 'classic' agonist quality of activating RAR $\gamma$-dependent transcriptional regulation, also has concomitant unknown, but likely RARindependent apoptotic activities. Dissection of these two pathways may provide new insights in retinoid-dependent signaling which could also have clinical implications. For instance, CD437 may be efficacious in instances where RA is not exerting any effect; melanoma cells such as A375 are resistant to RA but are still responsive to CD437. 
A large number of studies have been reported on the activity of CD437 on a variety of different tumor cells, but unfortunately these have failed to reveal a shared mechanism. In this report we have identified a novel pathway which can provide an explanation for these observations. RA and CD437 both act as agonists for RAR $\gamma$ which results in slow growth-arrest, likely due to suppression of several critical cell cycle regulators, ${ }^{11}$ and which in turn may mark the start of differentiation. The other, concomitant pathway is a DNA adduct-forming activity associated with CD437-dependent apoptosis which likely occurs without involvement of $\operatorname{RAR} \gamma$, which is also consistent with our finding that the $\operatorname{RAR} \beta / \gamma$ antagonist CD2366 does not block the induction of CITs and apoptosis by CD437 (data not shown). Several lines of evidence suggest that adduct-formation lies at the basis of CD437mediated apoptosis. First, the adduct appears within $8 \mathrm{~h}$ of treatment with CD437, at a point coincident with the onset of apoptosis; ${ }^{11}$ secondly, non-apoptotic retinoids RA and CD666 do not cause formation of this adduct, and finally, all CITs are DNA damage-response genes and ei24 is a critical mediator of apoptosis. Although alternative mechanisms cannot be completely ruled out, ${ }^{40}$ we believe that our data can be most readily explained by this interpretation. The DNA damage-sensing mechanism in S91 cells then triggers induction of CITs which has dramatic effects on cell physiology. Induction of $\mathrm{p} 21^{\mathrm{WAF} 1 / \mathrm{CIP} 1}$ is most likely responsible for growth-arrest in early S-phase, but not apoptosis, consistent with a report by Li et al. who showed that $\mathrm{p} 21^{\mathrm{WAF} 1 / \mathrm{CIP} 1}$ is not required for CD437-mediated apoptosis of lung cancer cells. ${ }^{17}$ Elevated levels of ei24 appear to relay a critical apoptotic signal although the mechanism of action of this effector remains to be established. ${ }^{31}$ The functional role of the other three CITs in S91 cells is much less clear. For instance, the primary

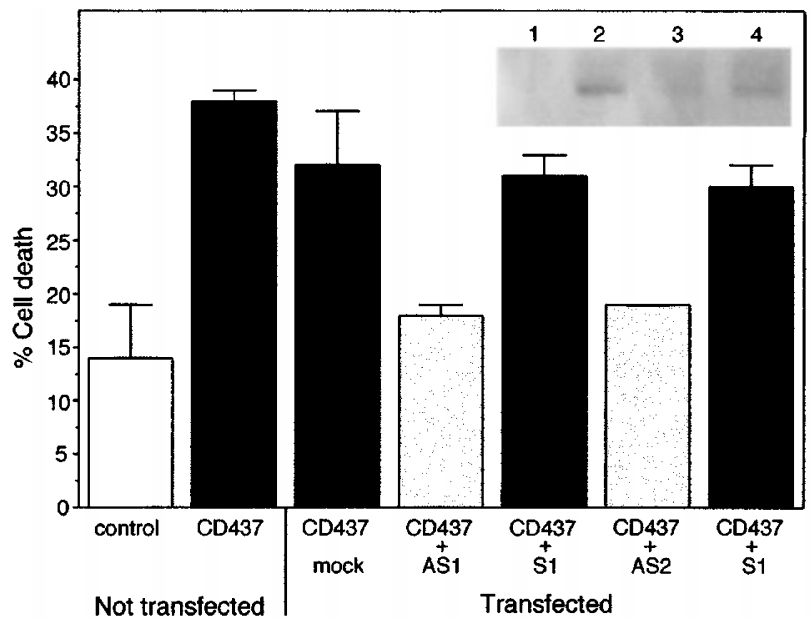

Figure 5 Antisense oligonucleotides against ei24 abrogate CD437dependent apoptosis of S91 cells. Two different anti-sense (AS1 and AS2), but not control sense (S1 and S2) oligonucleotides $(5 \mu \mathrm{M})$ block CD437induced cell death as measured by trypan-blue staining. Inset: Western blot showing that AS2 blocks expression of transfected, FLAG-tagged ei24. Lane 1 , control-transfected cells; lanes $2-4$, ei24-transfected cells in the absence (lane 2) or presence of $5 \mu \mathrm{M}$ and $2.5 \mu \mathrm{M}$ AS2 (lanes 3 and 4 , respectively) function of MDM2 is to impair p53-activity ${ }^{27}$ and induction of $M D M 2$ has been generally linked to protection from, rather than induction of, apoptosis. ${ }^{41-44}$ However, our data suggest that, unlike some other cell types, ${ }^{16,18,21}$ CD437mediated regulation of CITs is largely p53-independent in S91 cells, and induction of ei24 may bypass this pathway altogether. Alternative, p53-independent mechanisms have already been known to exist for, for instance, induction of p21 WAF1/CIP1 and MDM2. ${ }^{45-48}$ The functional significance of increased levels of cyclin G1 and TEAP mRNA in S91 cells also remains to be established.

CD437 caused DNA adduct-formation in neuroectodermal S91 melanoma cells and in mesenchymal 3T3 fibroblasts which indicates that this process can occur in highly divergent cell types. In contrast, the genetic response to this effect appears highly cell type-specific. For instance, in lung cancer cells, AP-1 and NUR77 are critical for CD437-mediated apoptosis ${ }^{17}$ and in $T$ cell lymphomas caspase- 3 is directly activated by CD437, ${ }^{26,49}$ whereas in S91 cells we were unable to detect induced expression, DNA-binding or transactivational activity by AP1 (data not shown) and CD437-mediated apoptosis does not appear to be associated with major changes in the Bcl2/Bax balance and/or caspase-3 activation. Other apoptosis-inducers have been recently identified which appear to act independently of these parameters, but at present it is unknown whether CD437 activates any down-stream mitochondrial effectors. ${ }^{50}$ Recently, a report by Marchetti et al. showed that CD437 can disrupt the inner mitochondrial transmembrane potential in myeloma cells resulting in generation of reactive oxygen species ${ }^{51}$ but no increase in reactive oxygen species levels could be detected in CD437-treated cells (data not shown). Our data nevertheless suggest that the majority of cell type-specific effects of CD437 reflect both common and differential biological responses to the same CD437-induced DNA adducts. Many of the transcripts previously reported to be induced by CD437 are known to be encoded by DNA damageresponse genes, such as $p 21^{W A F 1 / C I P 1}, A P-1, T P 53$, and GADD45. ${ }^{12,14-19,21,22,24}$

Our novel observations may aid in the development of a specific class of DNA adduct-and apoptosis-inducing synthetic retinoids for retinoid therapy of neoplastic disease whose activity is independent of RAR signaling. In this respect, it will be interesting to analyze the precise nature of the adduct induced by this novel activity of CD437. Additionally, CD437's p53-mimetic, yet p53independent activity may also have clinical potential in proliferative disorders where p53-activity is often lost due to genetic mutations.

\section{Materials and Methods}

\section{Cell culture}

S91 murine melanoma cells and Swiss 3T3 fibroblasts were grown in Dulbecco's modified Eagle's medium with $10 \%(\mathrm{v} / \mathrm{v})$ fetal calf serum and donor calf serum, respectively. A375 human melanoma cells were grown in RPMI medium 1640 with 10\% (v/v) fetal calf serum (Life 
Technologies, Grand Island, NY, USA) at $37^{\circ} \mathrm{C}$ in $5 \% \quad \mathrm{CO}_{2}$ in humidified air. Retinoid stock solutions (1 $\mathrm{mM})$ in dimethyl sulfoxide (DMSO) were added fresh to the media to a concentration of $1 \mu \mathrm{M}$, or $0.1 \%$ DMSO (control). RA was obtained from Sigma (St. Louis, MO, USA). CD437, CD666, Am580 and CD2314 were provided by Dr. U Reichert (Galderma R\&D Sophia Antipolis, France). 4-nitroquinoline $\mathrm{N}$-oxide (4NQ), $\mathrm{CHX}$ and Actinomycin $\mathrm{D}$ (Act) were obtained from Sigma (St. Louis, MO, USA).

\section{FACScan analysis}

Cells were grown and treated as indicated. Then cells were harvested, washed with phosphate buffered saline (PBS), and resuspended in $6.5 \mathrm{ml}$ Dulbecco's modified Eagle's medium and fixed with $3.5 \mathrm{ml}$ ethanol. Cells were resuspended in PBS with $8 \mu \mathrm{g} / \mathrm{ml}$ RNAse A and $18 \mu \mathrm{g} / \mathrm{ml}$ propidium iodide (PI), incubated for $30 \mathrm{~min}$ and DNA content was determined on a Becton Dickinson FACScan (Bedford, MA, USA).

\section{Plasmids and anti-sense oligonucleotides}

Plasmids pRARE ${ }_{3}$-Luc and p53RE-Luc were gifts from Drs. E Linney (Duke University, Durham, NC, USA) and J Xiao (Boston University School of Medicine, Boston, MA, USA). cDNA for TEAP was kindly provided by Dr. Carrier (Centre d'Immunologie INSERM-CNRS de Marseille-Luminy, Marseille, France). The prkMei24 plasmid, which expresses a FLAG epitope-tagged version of murine ei24, was a kind gift from Dr. Zambetti (St. Jude Children's Research Hospital, Memphis, TN, USA). All plasmids were isolated by Clontech plasmid kit (Palo Alto, CA, USA). Two phosophorothioate-modified oligodeoxynucleotides were designed to target ei24 mRNA around the AUG start codon and designated antisense ei24 oligonucleotide 1 (AS1) and antisense ei24 oligonucleotide 2 (AS2) together with two sense control oligonucleotides named S1 and S2, respectively (Life Technologies, Grand Island, NY, USA). AS1: 5'-CCATTCATCATGGAGGGC C, AS2: 5'-CCCCCAAACCATTCATCAT, S1: 5'-GGCCCTCCATGATGAATGG, S2: 5'-ATGATGAATGGTTTGGGGG.

\section{DNA adduct assay}

S91 and 3T3 cells were plated on $10 \mathrm{~cm}$ dishes and treated with the appropriate retinoids at $1 \mu \mathrm{M}$ for $8 \mathrm{~h}$. Genomic DNA was then isolated (DNeasy Tissue kit, Qiagen, Valencia, CA, USA) and the DNA concentration was measured spectrophotometrically. Detection of ${ }^{32}$ P-labeled DNA adducts was detected as described. ${ }^{33}$ Briefly, DNA was fully digested by micrococcal endonuclease and spleen exonuclease cleavage (Sigma, St. Louis, MO, USA), after which the digests were labeled with ${ }^{32} \mathrm{P}$ in the presence of $\mathrm{T} 4$ Polynucleotide kinase (New England Biolabs, Beverly, MA, USA). Separation of adduct from unmodified deoxynucleotides was achieved by polyethyleneimine-cellulose thin layer chromatography (JT Baker, Phillipsburg, NJ, USA) in 4-D development followed by autoradiography to detect the DNA adducts.

\section{Transfections}

Reporter plasmid transfections and Luciferase (Luc) assays were done as described before, ${ }^{11}$ except that appropriate ligands were added $32 \mathrm{~h}$ after electroporation for an additional $16 \mathrm{~h}$ before harvesting, and normalization of Luc values by protein concentration determination (Pierce, Rockford, IL, USA). The retroviral constructs expressing E6 have been previously described. ${ }^{52}$ Permanently transfected cells were selected and maintained in $600 \mu \mathrm{g} / \mathrm{ml} \mathrm{G418}$
(Life Technologies, Grand Island, NY, USA). Lipofectin was used for transfections with antisense or sense oligonucleotides according to the manufacturer's protocol (Life Technologies, Grand Island, NY, USA). After transfection, cells grown in normal medium for $24 \mathrm{~h}$, after which medium was replaced by medium with $1 \mu \mathrm{M}$ CD437. After $20 \mathrm{~h}$, cells were harvested and cell viability was analyzed by trypan Blue staining and whole cell extracts were made. Transfection of prkMei24 was done by using LipofectAMINE (Life Tech.) according to the manufacturer's recommendations (Life Technologies, Grand Island, NY, USA). Five $\mu \mathrm{g}$ empty vector of ei24 expression vector was used per $6 \mathrm{~cm}$ plate. After transfection, cells were grown in normal media and checked for the appearance of apoptotic cells (after $20 \mathrm{~h}$ ). Both attached and nonadherent cells were collected and analyzed by FACscan.

\section{RNA isolations and northern blot analysis}

Total RNA was isolated using Trizol (Life Technologies, Grand Island, NY, USA), poly (A) ${ }^{+}$RNA by PolyATract system (Promega, Madison, WI, USA). Blotting procedures, preparation of radioactively labeled probes, hybridization/washing conditions and quantitation by Phosphorlmager were performed as described, ${ }^{10}$ except that ExpressHyb was used (Clontech, Palo Alto, CA, USA).

\section{Western blot analysis and antibodies}

Whole cell extracts were made by lysing cells in $50 \mathrm{mM}$ Tris $\mathrm{pH} 8.0$ / $150 \mathrm{mM} \mathrm{NaCl} / 1 \mathrm{mM}$ EDTA/0.1\% NP40/50 mM NaF/1 mM NaVO $/ 2 \mu \mathrm{g} /$ $\mathrm{ml}$ aprotinin and leupeptin/0.2 mM PMSF. Protein concentrations were determined, and equal amounts of cell extract $(10-100 \mu \mathrm{g}$, depending on the protein of interest) were loaded and separated by $8-12 \%$ sodium dodecylsulfate-polyacrylamide gel electrophoresis, blotted onto polyvinylidene difluoride membranes (Bio-Rad, Hercules, CA, USA), sequentially immunoprobed with primary and horseradish peroxidase-coupled secondary antibody, and visualized by ECL Plus (Amersham Pharmacia, Piscataway, NJ, USA) and exposure on BioMax ML film (Kodak, Rochester, NY, USA) according to standard procedures. ${ }^{10}$ Antibodies were obtained from Santa Cruz (Santa Cruz, CA, USA), except for cyclin A (Sigma, St. Louis, MO, USA) and E (Oncogene, Cambridge, MA, USA), and FLAG (ZYMEK, San Francisco, CA, USA).

\section{Differential expression cloning and gene expression microarray analysis}

Poly $(\mathrm{A})^{+}$RNA was isolated from cells treated for $8 \mathrm{~h}$ with DMSO (control) or $1 \mu \mathrm{M} \mathrm{CD437,} \mathrm{and} \mathrm{the} \mathrm{Clontech} \mathrm{PCR-Select} \mathrm{cDNA}$ subtraction kit (Palo Alto, CA, USA) was used according to the manufacturer's protocol to obtain CD437-specific cDNA pools. cDNAs were cloned in pGEM-T (Promega, Wisconsin, MI, USA). For the Gene Expression Microarray analysis, poly $(A)^{+}$RNA from similarly-treated cells was isolated and subsequently analyzed by Genome Systems, St. Louis, MO, USA. The arrays contain about 8700 cDNAs. In all cases, regulation of new cDNAs was verified by Northern blot analysis, and sequenced when required.

\section{Acknowledgements}

We thank Douglas Faller for insightful comments, and Andrew Hsing and James Liu for technical assistance. This work was supported by a research grant from the National Institutes of Health CA76406 (to RA Spanjaard). 


\section{References}

1. Leid M, Kastner P and Chambon P (1992) Multiplicity generates diversity in the retinoic acid signalling pathways. Trends Biochem. Sci. 17: 427-433

2. Means AL and Gudas LJ (1995) The roles of retinoids in vertebrate development. Ann. Rev. Biochem. 64: 201-233

3. Amos B and Lotan R (1990) Retinoid-sensitive cells and cell lines. Methods Enzymol. 190: 217-225

4. Nagy L, Thomazy VA, Heyman RA and Davies PJ (1998) Retinoid-induced apoptosis in normal and neoplastic tissues. Cell Death Differ. 5: 11-19

5. Lotan R, Xu XC, Lippman SM, Ro JY, Lee JS, Lee JJ and Hong WK (1995) Suppression of retinoic acid receptor-beta in premalignant oral lesions and its upregulation by isotretinoin. N. Engl. J. Med. 332: 1405-1410

6. McBurney MW, Costa S and Pratt MA (1993) Retinoids and cancer: a basis for differentiation therapy. Cancer Invest. 11: 590-598

7. Spanjaard RA, Lee PJ, Sarkar S, Goedegebuure PS and Eberlein TJ (1997) Clone 10d/BM28 (CDCL1), an early S-phase protein, is an important growth regulator of melanoma. Cancer Res. 57: 5122-5128

8. Clifford JL, Petkovich M, Chambon P and Lotan R (1990) Modulation by retinoids of $\mathrm{mRNA}$ levels for nuclear retinoic acid receptors in murine melanoma cells. Mol. Endocrinol. 4: 1546-1555

9. Redfern CP, Daly AK, Latham JA and Todd C (1990) The biological activity of retinoids in melanoma cells. Induction of expression of retinoic acid receptorbeta by retinoic acid in S91 melanoma cells. FEBS Lett. 273: 19-22

10. Spanjaard RA, Sugawara A, Ikeda M and Chin WW (1995) Evidence that retinoid $\mathrm{X}$ receptors mediate retinoid-dependent transcriptional activation of the retinoic acid receptor beta gene in S91 melanoma cells. J. Biol. Chem. 270: 17429_ 17436

11. Spanjaard RA, Ikeda M, Lee PJ, Charpentier B, Chin WW and Eberlein TJ (1997) Specific activation of retinoic acid receptors (RARs) and retinoid $X$ receptors reveals a unique role for $R A R \gamma$ in induction of differentiation and apoptosis of $S 91$ melanoma cells. J. Biol. Chem. 272: 18990-18999

12. Hsu CA, Rishi AK, LiXS, Gerald TM, Dawson MI, Schiffer C, ReichertU, ShrootB, Poirer GC and Fontana JA (1997) Retinoid induced apoptosis in leukemia cells through a retinoic acid nuclear receptor-independent pathway. Blood 89: 4470 4479

13. Sun SY, Yue P, Shroot B, Hong WK and Lotan R (1997) Induction of apoptosis in human non-small cell lung carcinoma cells by the novel synthetic retinoid CD437. J. Cell. Physiol. 173: 279-284

14. Adachi H, Preston G, Harvat B, Dawson Ml and Jetten AM (1998) Inhibition of cell proliferation and induction of apoptosis by the retinoid AHPN in human lung carcinoma cells. Am. J. Respir. Cell. Mol. Biol. 18: 323-333

15. Fontana JA, Sun RJ, Rishi AK, Dawson MI, Ordonez JV, Zhang Y, Tschang SH, Bhalla K, Han Z, Wyche J, Poirer G, Sheikh MS, Shroot B and Reichert U (1998) Overexpression of bcl-2 or bcl-XL fails to inhibit apoptosis mediated by a novel retinoid. Oncol. Res. 10: 313-324

16. Hsu SL, Yin SC, Liu MC, Reichert U and Ho WL (1999) Involvement of cyclindependent kinase activities in CD437-induced apoptosis. Exp. Cell. Res. 252: $332-341$

17. LiY, Lin B, Agadir A, Liu R, Dawson MI, Reed JC, Fontana JA, Bost F, Hobbs PD, Zheng Y, Chen GQ, Shroot B, Mercola D and Zhang XK (1998) Molecular determinants of AHPN (CD437)-induced growth arrest and apoptosis in human lung cancer cell lines. Mol. Cell. Biol. 18: 4719-4731

18. Sun SY, Yue P, Wu GS, El-Deiry WS, Shroot B, Hong WK and Lotan R (1999) Mechanisms of apoptosis induced by the synthetic retinoid CD437 in human nonsmall cell lung carcinoma cells. Oncogene 18: 2357-2365

19. Zhang Y, Rishi AK, Dawson MI, Tschang, Farhana L, Boyanapalli M, Reichert U, Shroot B, Van Buren EC and Fontana JA (2000) S-phase arrest and apoptosis induced in normal mammary epithelial cells by a novel retinoid. Cancer Res. 60: 2025-2032

20. Sun SY, Yue P, Shroot B, Hong WK and Lotan R (1999) Implication of C-Myc in apoptosis induced by the retinoid CD437 in human lung carcinoma cells. Oncogene 18: $3894-3901$

21. Schadendorf D, Kern MA, Artuc M, Pahl HL, Rosenbach T, Fichtner I, Nurnberg W, Stuting S, von Stebut E, Worm M, Makki A, Jurgovsky K, Kolde G and Henz BM (1996) Treatment of melanoma cells with the synthetic retinoid CD437 induces apoptosis via activation of AP-1 in vitro, and causes growth inhibition in xenografts in vivo. J. Cell. Biol. 135: 1889-1898
22. Rishi AK, Sun RJ, Gao Y, Hsu CK, Gerald TM, Sheikh MS, Dawson MI, Reichert U, Shroot B, Jr AJ, Brewer G and Fontana JA (1999) Post-transcriptional regulation of the DNA damage-inducible gadd45 gene in human breast carcinoma cells exposed to a novel retinoid CD437. Nucleic Acids Res. 27: $3111-3119$

23. Hsu CA, Rishi AK, LiXS, Dawson MI, ReichertU, ShrootB andFontana JA (1997) $\mathrm{Bcl}-\mathrm{X}(\mathrm{L})$ expression and its downregulation by a novel retinoid in breast carcinoma cells. Exp. Cell. Res. 232: 17-24

24. Shao ZM, Dawson MI, Li XS, Rishi AK, Sheikh MS, Han QX, Ordonez JV, Shroot B and Fontana JA (1995) p53 independent G0/G1 arrest and apoptosis induced by a novel retinoid in human breast cancer cells. Oncogene 11: 493-504

25. Mologni L, Ponzanelli I, Bresciani F, Sardiello G, Bergamaschi D, Gianni M, Reichert U, Rambaldi A, Terao M and Garattini E (1999) The novel synthetic retinoid 6-[3-adamantyl-4-hydroxyphenyl]-2-naphthalene carboxylic acid (CD437) causes apoptosis in acute promyelocytic leukemia cells through rapid activation of caspases. Blood 93: 1045-1061

26. Piedrafita FJ and Pfahl M (1997) Retinoid-induced apoptosis and Sp1 cleavage occur independently of transcription and require caspase activation. Mol. Cell. Biol. 17: 6348-6358

27. Prives $C$ (1998) Signaling to p53: breaking the mdm2-p53 circuit. Cell 95: 5-8

28. Carrier A, Nguyen C, Victorero G, Granjeaud S, Rocha D, Bernard K, Miazek A, Ferrier P, Malissen M, Naquet P, Malissen B and Jordan BR (1999) Differential gene expression in CD3epsilon- and RAG1-deficient thymuses: definition of a set of genes potentially involved in thymocyte maturation. Immunogenetics 50 : $255-270$

29. Okamoto $K$ and Beach $D$ (1994) Cyclin $G$ is a transcriptional target of the p53 tumor suppressor protein. EMBO J. 13: 4816-4822

30. Lehar SM, Nacht M, Jacks T, Vater CA, Chittenden T and Guild BC (1996) Identification and cloning of El24, a gene induced by p53 in etoposide-treated cells. Oncogene 12: 1181-1187

31. Gu Z, Flemington C, Chittenden T and Zambetti GP (2000) ei24, a p53 response gene involved in growth suppression and apoptosis. Mol. Cell. Biol.20:233-241

32. Bernard BA, Bernardon JM, Delescluse C, Martin B, Lenoir MC, Maignan J, Charpentier B, Pilgrim WR, Reichert U and Shroot B (1992) Identification of synthetic retinoids with selectivity for human nuclear retinoic acid receptor gamma. Biochem. Biophys. Res. Commun. 186: 977-983

33. Gupta RC, Reddy MV and Randerath K (1982) ${ }^{32} \mathrm{P}$-postlabeling analysis of nonradioactive aromatic carcinogen-DNA adducts. Carcinogenesis 3: 1081-1092

34. Juven T, BarakY,Zauberman A, George DL and Oren M(1993)Wild type p53can mediate sequence-specific transactivation of an internal promoter within the mdm2 gene. Oncogene 8: 3411-3416

35. Harper JW, Adami GR, Wei N, Keyomarsi Kand Elledge SJ (1993) The p21 Cdkinteracting protein $\mathrm{Cip} 1$ is a potent inhibitor of $\mathrm{G} 1$ cyclin-dependent kinases. Cell 75: $805-816$

36. Xiong Y, Hannon GJ, Zhang H, Casso D, Kobayashi Rand Beach D (1993) p21 is a universal inhibitor of cyclin kinases. Nature 366: 701-704

37. King RW, Jackson PK and Kirschner MW (1994) Mitosis in transition. Cell 79: $563-571$

38. Liu M, lavarone A and Freedman LP (1996) Transcriptional activation of the human p21 (WAF1/CIP1) gene by retinoic acid receptor. Correlation with retinoid induction of U937 cell differentiation. J. Biol. Chem. 271: 31723-31728

39. Strasberg RieberMandRieber M (1995) Suppression of cyclin D1 but not cdk4 or cyclin A with induction of melanoma terminal differentiation. Biochem. Biophys. Res. Commun. 216: 422-427

40. Quash G, Roch AM, Chantepie J, Michal Y, Fournet G and Dumontet C (1995) Methional derived from 4-methylthio-2-oxobutanoate is a cellular mediator of apoptosis in BAF3 lymphoid cells. Biochem J. 305: 1017-1025

41. HauptY,Barak Y and Oren M(1996) Cell type-specific inhibition of p53-mediated apoptosis by mdm2. EMBO. J. 15: 1596-1606

42. Kondo S, Barnett GH, Hara H, Morimura T and Takeuchi J (1995) MDM2 protein confers the resistance of a human glioblastoma cell line to cisplatin-induced apoptosis. Oncogene 10: 2001-2006

43. Meng RD, Shih H, Prabhu NS, George DL and El-Deiry WS (1998) Bypass of abnormal MDM2 inhibition of p53-dependent growth suppression. Clin Cancer Res. 4: 251-259

44. Teoh G, Urashima M, Ogata A, Chauhan D, DeCaprioJA, Treon SP, Schlossman $\mathrm{RL}$ and Anderson K (1997) MDM2 protein overexpression promotes proliferation and survival of multiple myeloma cells. Blood 90: 1982-1992 
45. Bellido T, O'Brien CA, Roberson P and Manolagas (1998) Transcriptiona activation of the $\mathrm{p} 21$ (WAF1,CIP1,SDI1) gene by interleukin- 6 type cytokines. A prerequisite for their pro-differentiating and anti-apoptotic effects on human osteoblastic cells. J. Biol. Chem. 273: 21137-21144

46. Jiang H, Lin J, Su ZZ, Collart FR, Huberman E and Fisher PB (1994) Induction of differentiation in human promyelocytic HL-60 leukemia cells activates p21, WAF1/CIP1, expression in the absence of p53. Oncogene 9: 3397-3406

47. Macleod KF, Sherry N, Hannon G, Beach D, Tokino T, Kinzler K, Vogelstein B and Jacks $T$ (1995) p53-dependent and independent expression of p21 during cell growth, differentiation, and DNA damage. Genes Dev. 9: 935-944

48. Wu L and Levine AJ (1997) Differential regulation of the p21/WAF-1 and mdm2 genes after high-dose UV irradiation: p53-dependent and p53-independent regulation of the mdm2 gene. Mol. Med. 3: 441-451

49. Adachi H, Adams A, Hughes FM, Zhang J, Cidlowski JA and Jetten AM (1998) Induction of apoptosis by the novel retinoid AHPN in human T-cell lymphoma cells involves caspase-dependent and independent pathways. Cell. Death Differ. 5: $973-983$
50. Susin SA, Lorenzo HK, Zamzami N, Marzo I, Snow BE, Brothers GM, Mangion J, Jacotot E, Costantini P, Loeffler M, Larochette N, Goodlett DR, Aebersold R, Siderovski DP, Penninger JM and Kroemer G (1999) Molecular characterization of mitochondrial apoptosis-inducing factor. Nature 397: 441-446

51. Marchetti P, Zamzami N, Joseph B, Schraen-Maschke S, Mereau-Richard C, Constantini P, Metivier D, Susin SA, Kroemer G and Formstecher P (1999) The novel retinoid 6-[3-(1-adamantyl)-4-hydroxyphenyl]-2-naphtalene carboxylic acid can trigger apoptosis through a mitochondrial pathway independent of the nucleus. Cancer Research 59: 6257-6266

52. Vaziri C, Stice L and Faller DV (1998) Butyrate-induced G1 arrest results from p21-independent disruption of retinoblastoma protein-mediated signals. Cell Growth Differ. 9: 465-474 